\title{
Mental health, quality of life and optimism during the covid-19 pandemic: a comparison between Brazil and Portugal
}

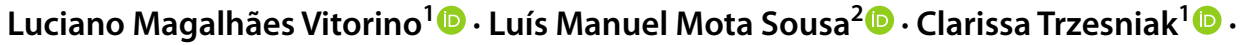

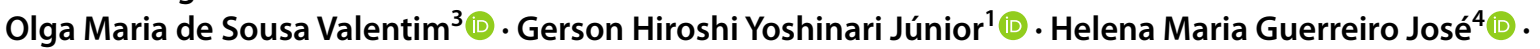 \\ Giancarlo Lucchetti ${ }^{5}$
}

Accepted: 31 October 2021 / Published online: 8 November 2021

(c) The Author(s), under exclusive licence to Springer Nature Switzerland AG 2021

\begin{abstract}
Purpose Although there have been numerous studies investigating the mental health of individuals during the pandemic, a comparison between countries is still scarce in the literature. To explore this gap, the present study aimed to compare the mental health (i.e., anxiety and depression), quality of life (QoL), and optimism/pessimism among individuals from Brazil and Portugal during the COVID-19 pandemic and the associated factors.

Method A cross-sectional population-based study was conducted during the COVID-19 pandemic in Brazil and Portugal. Data collection was carried out between May and June 2020, using an online form which was sent through social networks. A total of 2069 participants (1156 from Brazil and 913 from Portugal) were included. Depressive symptoms (PHQ-9), Anxiety (GAD-7), optimism/pessimism (Revised Life Orientation Test - LOT), QoL (WHOQOL-Bref), and sociodemographic, health, and social distancing variables were assessed. Data was analyzed using univariate and multivariate models.

Results There were remarkable differences between Brazil and Portugal in all outcomes during the COVID-19 pandemic, including higher levels of depressive symptoms, anxiety, and optimism for the Brazilian individuals and higher levels of QoL and pessimism for the Portuguese individuals. The following factors were associated with the mental health and QoL in both Brazilian and Portuguese populations: gender, age, being a healthcare professional, and days in social distancing.

Conclusion Despite the fact that Brazilians were more optimistic during the COVID-19 pandemic, they had lower levels of mental health and QoL as compared to the Portuguese individuals.
\end{abstract}

Keywords Coronavirus disease (COVID-19) · Quarantine $\cdot$ Mental health $\cdot$ Quality of life, social distancing

Luciano Magalhães Vitorino

lucianoenf@yahoo.com.br

Luís Manuel Mota Sousa

luismmsousa@gmail.com

Clarissa Trzesniak

clarissaf@hotmail.com

Olga Maria de Sousa Valentim

ommvalentim3@gmail.com

Gerson Hiroshi Yoshinari Júnior

gerson.junior@fmit.edu.br

Helena Maria Guerreiro José

helenamgjose@gmail.com

Giancarlo Lucchetti

g.lucchetti@yahoo.com.br
1 Faculty of Medicine of Itajubá-Afya Group, Rennó Júnior avenue, 368, Itajubá, Minas Gerais, Brazil

2 Nursing Department, Comprehensive Health Research Centre, University of Évora, Évora, Portugal

3 Instituto Politécnico de Leiria, ESSLei Escola Superior de Saúde, Centro de Investigação Em Tecnologias E Serviços de Saúde (CINTESIS, Grupo NursID), Leiria, Portugal

4 Universidade Do Algarve, The Health Sciences Research Unit: Nursing, Faro, Portugal

5 School of Medicine, Federal University of Juiz de Fora, Juiz de Fora, Brazil 


\section{Background}

The world is experiencing rapidly changes with the emergence of the COVID-19, a respiratory disease caused by the virus SARS-CoV-2. This disease has spread globally, leading to remarkable transformations in healthcare systems, as well as in the way people interact with each other [1]. After the beginning of COVID-19 in China; Europe has been drastically affected by the coronavirus [2], and countries such as Spain, United Kingdom, Italy, and Portugal suffered a great number of cases. After this European wave, the pandemic has rapidly spread to North and Latin America, resulting in an increase number of cases and deaths in the United States and also in Brazil [3, 4].

The way countries and governments handled the COVID-19 pandemic have probably influenced the number of coronavirus cases and deaths for each country. In this scenario, two countries with the same cultural roots, but from different continents (i.e., Brazil and Portugal) may serve as important models for understanding further the pandemic. On the one hand, COVID-19 cases in Portugal began on March 2nd, 2020. In a rapid response, the Portuguese government installed a state of emergency on March 18th. Likewise, a set of measures to contain the transmission of the new Coronavirus was implemented, such as the compulsory confinement at home or in a health facility; mandatory home office (except for essential workers); prohibition of face-to-face meetings; limitation of travel; closure or limitation of commercial activities; cross-border controls; and prohibition of large religious events and celebrations [5]. Up to July 2021, Portugal has recorded 1693 deaths/1 million population (data available at https://www. worldometers.info/coronavirus/).

On the other hand, the first case of COVID-19 officially registered in Brazil was on February 25th, 2020. The government did not impose a structured confinement or any other restrictive strategies to avoid the dissemination of the new Coronavirus. This resulted in disorganized rules for each state of the country and generic recommendations for the population, such as washing hands, wearing masks, and avoiding social interaction [6, 7]. Unfortunately, these problems made Brazil one of the epicenters of the pandemic. Up to July 2021, Brazil has recorded 2535 deaths/1 million population (data available at https://www.world ometers.info/coronavirus/).

Scientific evidence has suggested that most of the mental health impact of COVID-19 is caused by one of the few effective strategies proposed to avoid its dissemination, i.e., social distancing [8]. Recent studies have shown that self-isolation, lockdown, quarantine, and social distancing may have an influence on the mental health of the general population and healthcare professionals $[9,10]$, which is in accordance with several Brazilian studies that have identified that social distancing has been associated with the mental health and quality of life (QoL) of Brazilians [11]. A Brazilian cross-sectional community-based online survey identified a high prevalence of depression, anxiety, and impaired QoL during the first wave of the COVID-19 pandemic [12]. Same results were also identified in Portugal, showing that the mental health and QoL of the Portuguese population were also impaired during the COVID-19 pandemic, mostly affecting women, loweducated individuals, and older persons [13].

Although most authors agree that there is an increase in the prevalence of anxiety, fear, depressive symptoms, and stress; and a decrease in QoL during the pandemic, these numbers are greatly influenced by biological, geographic, cultural, and political factors $[14,15]$. Pre-pandemic information from the World Health Organization (WHO) [16] has already documented differences concerning mental health issues between both countries. Although the Brazilian and Portuguese populations had a similar prevalence of depressive symptoms (i.e. 5.8\% and 5.7\%, respectively), anxiety symptoms were higher among Brazilians (9.3\%) as compared to Portuguese individuals (4.9\%) and the QoL was lower in Brazil as well.

In the context of COVID-19, it is important to understand how the pandemic influences mental health according to the different cultural backgrounds [17]. Although there are already numerous studies investigating the mental health of individuals during the pandemic in different cultures [18, 19], a comparison between countries from Latin America and Europe, which included large sample sizes, in the same time periods and which used the same instruments to assess mental health, QoL, and optimism/pessimism is scarce in the literature [20].

In order to bridge this gap concerning the differences of mental health disorders in geographically distant populations, the present study aims to compare the mental health (anxiety and depression), quality of life, and optimism/pessimism between individuals from Brazil and Portugal during the COVID-19 pandemic and their associated factors. These results may increase the knowledge and promote discussion on the risk and protective factors for mental health and QoL in countries from different continents and with different cultures.

\section{Methods}

This is a cross-sectional exploratory population-based online study carried out during the COVID-19 pandemic (in the months of May and June 2020) including two Portuguesespeaking countries (i.e. Brazil and Portugal). Brazil and Portugal were chosen due to the following similarities and 
differences between countries: same language (Portuguese), same cultural roots (Brazil was once a colony of Portugal), different approaches to the pandemic (Portugal more restrictive and Brazil less restrictive), geographic distance (South America and Europe) and differences on personality. The study was approved by the Brazilian National Health Council/Ministry of Health (\#4010466) for data collection in Brazil and by the Research Ethics Committee of the University of Algarve (CEUAlg Pn.1/2020) for data collection in Portugal. All participants gave informed consent online and, all procedures were carried out in accordance to the Brazilian and Portuguese ethical regulations and the 1964 Helsinki Declaration.

\section{Eligibility criteria}

Participants were eligible if they were: 18 years old or more, Brazilian or Portuguese citizens, living in Brazil or Portugal during the COVID-19 pandemic and in social alteration due to the pandemic (for at least 15 days or more). The term social alteration was used for all individuals that suffered a change in their social statues due to the pandemic. This embraces individual in home quarantine (i.e., when a person might have been exposed to the virus, but is not ill), in isolation (i.e. separation of ill persons with contagious diseases from others for the purpose of protecting noninfected persons) and in social distancing (i.e., voluntary isolation to minimize interactions between persons) [21]. Social distancing was considered if the participant reported staying at home most of the time unless he or she needed to go out for certain reasons, such as buying food or going to the pharmacy or healthcare services, with the exception of health professionals, which are considered essential workers and not subjected to the restriction, unless if they became infected. Participants with incomplete questionnaires (i.e. did not answer all items/sections of the questionnaire) were excluded. In the case of duplicate forms, we considered only the first response of the participant. Forms in which the term of consent was not accepted were also excluded.

\section{Procedures}

Data collection were carried out online using strategies such as convenience sampling and snowball technique [22]. Face to face data collection was not possible at that moment due to the mandatory social distancing rules and the risk of infection for participants and research assistants in both countries. Brazilian data collection was carried out between May 11th and June 3rd, 2020, using an online electronic form (Google Forms ${ }^{\circledR}$ ). Data collection started three months after the sanction of the Brazilian law, which regulates the quarantine period and the specific measures against the new Coronavirus. Portuguese data collection was carried out between May 6th and May 31st, 2020, using the same online electronic form (Google Forms ${ }^{\circledR}$ ). Data collection started 52 days after the beginning of the quarantine period and the specific measures against the new Coronavirus.

In both cases, the link to the questionnaire was advertised and randomly sent through social networks (Facebook, Instagram, and WhatsApp), and the average time to fulfill the forms was less than $15 \mathrm{~min}$. The questionnaire was divided into 5 sections and all items for each section were forced (i.e. required). A single question was created at the end of each section allowing participants to edit their responses and coming back later to the questionnaire. Therefore, a participant could complete a section and return later to the other sections or complete the entire questionnaire in a single moment. For the present study, however, only those who completed all five sections were included as reported in the Eligibility criteria.

\section{Measures}

The following instruments validated into Portuguese were used for both countries:

- The Patient Health Questionnaire [23, 24](PHQ-9) was used to assess depressive symptoms in the past two weeks. It is a self-report questionnaire that asks about the nine major depression disorder items defined by the Diagnostic and Statistical Manual of Mental Disorders (DSM-5). For each item, responses are rated on a 4-point Likert scale, ranging from 0 ("Not at all") to 3 ("Almost every day"). Higher scores represent increased levels of depressive symptoms, which can vary from 0 to 27 [24]. It was adopted a cut-off point $\geq 10$ points to indicate the presence of depressive symptoms ("moderate," "moderately severe," and "severe cases") [23].

- The 7-item Generalized Anxiety Disorder Scale (GAD-7) [25] is a self-administered questionnaire to assess symptoms related to generalized anxiety disorder in the last two weeks. For each of the seven items, the responses are classified into a 4-point Likert scale, ranging from 0 ("Not at all") to 3 ("Almost every day"). Higher scores represent increased levels of anxiety symptoms, varying from 0 to 21 . We adopted a cut-off point $\geq 10$ points to identify anxiety disorder cases ("moderate" and "severe" cases) [26].

- Optimism and pessimism assessed by the Revised Life Orientation Test (LOT-R) [27], validated into Portuguese. This instrument appraises individual differences in optimism/pessimism and has ten items, consisting of three that assess optimism, three related to pessimism, and four padding items that are not included in the analysiss. Each item is classified on a 5-point Likert scale ranging from 0 ("strongly disagree") to 4 ("strongly 
agree"). The total scale score is calculated by summing the optimism and the inverted pessimism raw subscales [27].

- The World Health Organization Quality of Life (WHO$Q O L-B R E F)[28,29]$ is a generic quality of life instrument that contains 26 items on a 5-point Likert scale, ranging from 1 to 5 . The following four domains are covered: physical, psychological, social relations, and environment. While the first two items are generic, the other 24 belong to one of the mentioned domains that make up the original instrument. Higher scores represent better self-perception of quality of life. However, there is no cut-off point for its classification [28, 29].

- Sociodemographic, health, and social alteration variables: age (years); social distancing duration (days); sex (male or female); marital status (with a partner; no partner); Self-reported Physical Activity: "During quarantine or social distancing. Are you doing physical activity regularly (at least 3 times a week)? (yes or no); chronic illness (yes or no); use of daily medications (yes or no); Alcohol use: "Do you use alcohol at least 3 times a week ?"'(yes or no); Consultation with a doctor or psychologist: "Did you need clinical consultation with a doctor or psychologist during quarantine or social distancing?" (yes or no); Primary Care unit use: "Did you use any Primary Care Health Unit during quarantine or social distancing?" (yes or no); being a health professional (yes or no) and; having any family member or friend who has or had COVID-19 (yes or no).

\section{Sample size}

Sample size was calculated a priori using $\mathrm{G} \times$ Power 3.1.9.7 software. In the case of depressive and anxiety symptoms, the effect sizes were based on the minimal clinically important differences (MCID) for depressive symptoms (Cohen $\mathrm{d}=0.24$ ) [30] and anxiety (Cohen $\mathrm{d}=0.29$ ) [31]. In order to perform a univariate General Linear Modeling (GLM) between the most conservative effect size (Cohen $d=0.24$; i.e., $\mathrm{f}=0.12$ ), including 10 independent variables, $\alpha=0.05$ and a power of $95 \%$, the minimum sample required was 906 participants. In the case of quality of life, we adopted a MCID f-squared of 0.02 (equivalent to Cohen $d=0.20$ )[32]. In order to perform a multivariate General Linear Modeling (GLM), including 10 independent variables, $\alpha=0.05$ and a power of $95 \%$, the minimum sample required was 1230 participants.

\section{Data analysis}

Data were analyzed using the Statistical Package for Social Sciences-SPSS 23 (SPSS Inc.). First, sociodemographic variables, health aspects, social distancing characteristics, mental health, and quality of life were reported.

Then, a general linear model (GLM) was carried out, treating "country" as a fixed factor (Brazil-0; Portugal=1). Univariate GLM was used to perform a comparison of scores for depressive symptoms, anxiety, optimism, pessimism and multivariate GLM for QoL domains. The results were presented with means, standard error (SE), 95\% confidence intervals (CI), and effect sizes. The means scores were controlled for all covariates: age, sex, duration of social distancing (in days), marital status, physical activity, daily medication, alcohol use, doctor/psychologist consultation, healthcare professional, and friend or family member with COVID-19. Cohen's d test was used to determine effect sizes: small $(d \leq 0.2)$, medium $(d \cong 0.5)$, and large $(d \geq 0.8)$ effects.

Pearson's correlation was performed between continuous independent variables (age and social distancing duration in days) and dependent variables. In multivariate analysis, Univariate GLM and multivariate GLM were used for assessing the interaction effect of a specific country and covariates (i.e., age, quarantine duration, physical activity, alcohol use, and chronic illness) and dependent variables. GLM analyses were evaluated for linearity, multicollinearity, homogeneity of variance-covariance matrices, and extreme values. For all analyses, the alpha level for statistical significance was set at $p<0.05$ (two-tailed).

\section{Results}

The whole sample comprised a total of 2097 participants, 1167 from Brazil and 930 from Portugal. After removing missing data $(n=21)$ and duplicate forms $(n=7) ; 2069$ participants remained: 1156 Brazilian individuals (from 22 out of the 27 Brazilian states and 196 cities) and 913 Portuguese individuals (from all the five Portuguese regions and all the 17 districts). Table 1 presents sociodemographic and clinical information for all subjects. The Portuguese participants were significantly older, had been in quarantine for a lower amount of time, had more male respondents, were practicing physical activity more frequently and had more healthcare professionals among the participants (all $p \leq 0.001$ ). Brazilians, in turn, had more respondents without a partner, were taking more daily use medications, had more participants who went to a Doctor/Psychologist during the pandemic, more people who had friends/family members with COVID19 , and used more alcohol (all $p<0.001$ ). Likewise, Brazilians showed more depression (PHQ- $9 \geq 10)(p=0.003)$ and a higher frequency of anxiety disorders (GAD-7 $\geq 10$ ) $(p<0.001)$.

The comparison between countries can be better visualized in Table 2. There were significant differences in all 
Table 1 Sociodemographic and clinical profile of Brazilian and Portuguese samples during COVID-19 pandemic

\begin{tabular}{|c|c|c|c|c|}
\hline Variables & Total sample $(n=2069)$ & Brazilian $(n=1156)$ & Portuguese $(n=913)$ & $p$-value \\
\hline & Mean (SD) & Mean (SD) ${ }^{a}$ & Mean $(S D)^{\mathrm{a}}$ & \\
\hline Age & $39.77(13.86)$ & $37.58(13.99)$ & $42.55(13.18)$ & $<0.001$ \\
\hline \multirow[t]{2}{*}{ Social distancing duration (days) } & $43.70(22.39)$ & $46.52(20.93)$ & $40.14(23.63)$ & $<0.001$ \\
\hline & $n(\%)$ & $n(\%)^{\mathrm{b}}$ & $n(\%)^{\mathrm{b}}$ & \\
\hline \multicolumn{5}{|l|}{ Sex } \\
\hline Male & $606(29.28)$ & $351(30.36)$ & $255(59.70)$ & $<0.001$ \\
\hline Female & $1463(70.72)$ & $805(69.63)$ & $368(40.30)$ & \\
\hline \multicolumn{5}{|l|}{ Marital status } \\
\hline With a partner & $1081(52.20)$ & $566(48.96)$ & $515(56.41)$ & $<0.001$ \\
\hline No partner & $988(47.80)$ & $590(51.04)$ & $398(43.59)$ & \\
\hline \multicolumn{5}{|l|}{ Physical activity } \\
\hline Yes & $789(38.14)$ & $388(33.56))$ & $401(43.92)$ & $<0.001$ \\
\hline No & $1280(61.86)$ & $768(66.44)$ & $388(56.08)$ & \\
\hline \multicolumn{5}{|l|}{ Chronic illness } \\
\hline Yes & $503(24.31)$ & $274(23.70)$ & $229(25.08)$ & 0.250 \\
\hline No & $1566(75.69)$ & $882(76.30)$ & $684(74.92)$ & \\
\hline \multicolumn{5}{|l|}{ Daily medication } \\
\hline Yes & $885(42.78)$ & $619(53.55)$ & $348(38.11)$ & $<0.001$ \\
\hline No & $1184(57.22)$ & $537(46.45)$ & $565(61.89)$ & \\
\hline \multicolumn{5}{|l|}{ Alcohol use } \\
\hline Yes & $902(43.60)$ & $758(65.57)$ & $504(52.20)$ & $<0.001$ \\
\hline No & $1167(56.40)$ & $398(34.43)$ & $409(47.80)$ & \\
\hline \multicolumn{5}{|l|}{ Doctor/psychologist consultation } \\
\hline Yes & $390(18.85)$ & $288(24.91)$ & 102 (11.17) & $<0.001$ \\
\hline No & $1679(81.15)$ & $868(75.09)$ & $811(88.83)$ & \\
\hline \multicolumn{5}{|l|}{ Primary health care unit } \\
\hline Yes & $270(13.05)$ & $138(11.94)$ & $132(14.45)$ & 0.052 \\
\hline No & 1799 (86.95) & $1018(88.06)$ & $781(85.55)$ & \\
\hline \multicolumn{5}{|l|}{ Healthcare professional } \\
\hline Yes & $768(37.12)$ & $396(34.25)$ & $372(40.45)$ & 0.001 \\
\hline No & $1301(62.88)$ & $760(65.75)$ & $541(59.55)$ & \\
\hline \multicolumn{5}{|l|}{ Friend/Family with COVID-19 } \\
\hline Yes & $455(22.00)$ & $323(27.94)$ & $132(14.46)$ & $<0.001$ \\
\hline No & $1614(78.00)$ & $833(72.06)$ & $781(85.54)$ & \\
\hline \multicolumn{5}{|l|}{ Depressive symptoms (PHQ-9 $\geq 10$ ) } \\
\hline Yes & $812(39.25)$ & $484(41.86)$ & $328(35.92)$ & 0.003 \\
\hline No & $1257(60.75)$ & $672(58.13)$ & $585(64.08)$ & \\
\hline \multicolumn{5}{|l|}{ Anxiety (GAD-7 $\geq 10)$} \\
\hline Yes & $519(25.08)$ & $335(28.98)$ & $184(20.15)$ & $<0.001$ \\
\hline No & $1550(79.92)$ & $821(71.02)$ & $729(79.85)$ & \\
\hline
\end{tabular}

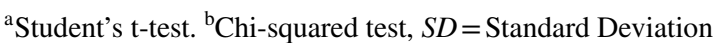

outcomes, including higher levels of depressive symptoms $(d=0.15)$, anxiety $(d=0.13)$ and optimism $(d=0.47)$ for the Brazilian individuals and higher levels of quality of life $(0.14<d<0.42)$ and pessimism $(d=0.31)$ for the Portuguese individuals, even after controlling for covariates.

The results obtained through the bivariate analysis using Student's $t$ tests for the mental health and QoL domains are shown in the Supplementary Material. Table 3 compares the variables associated with mental health and optimism/ pessimism between countries. In univariate GLM regression, the PHQ-9 $(\mathrm{F}=4.091 ; p<0.001)$, the GAD-7 $(\mathrm{F}=4.203$; $p<0.001)$, the Optimism LOT-R $(\mathrm{F}=8.302 ; p<0.001)$, and the Pessimism LOT-R $(\mathrm{F}=5.295 ; p<0.001)$ had significant main effects, showing that there are differences 
Table 2 Marginal Mean of mental health and quality of life of Brazilian and Portuguese samples during COVID-19 pandemic $(N=2069)$

\begin{tabular}{|c|c|c|}
\hline Variables & $\begin{array}{l}\text { Brazilian }(n=1156) \\
\operatorname{Mean}^{\mathrm{a}}(\mathrm{SE}) \mathrm{CI} 95 \%\end{array}$ & $\begin{array}{l}\text { Portuguese }(n=913) \\
\operatorname{Mean}^{\mathrm{a}}(\mathrm{SE}) \text { CI } 95 \%\end{array}$ \\
\hline \multicolumn{3}{|l|}{ PHQ-9 } \\
\hline \multicolumn{3}{|l|}{ GAD-7 } \\
\hline \multicolumn{2}{|l|}{ LOT-R } & $6.28(0.190) 5.97-6.61$ \\
\hline Optimism & $8.62(0.084) 8.46-8.77$ & $7.28(0.095) 7.07-7.48$ \\
\hline Pessimism & $7.51(0.081) 7.36-7.66$ & $8.36(0.091) 8.18-8.54$ \\
\hline \multicolumn{3}{|l|}{ WHOQOL-Bref } \\
\hline Physical health & $14.72(0.074) 14.56-14.88$ & $15.76(0.084) 15.61-15.90$ \\
\hline Psychological & $14.16(0.082) 19.99-14.33$ & $15.01(0.093) 14.83-15.19$ \\
\hline Social relationships & $13.88(0.102) 13.67-14.08$ & $14.36(0.115) 14.13-14.59$ \\
\hline Environment & $14.67(0.072) 14.52-14.81$ & $15.01(0.082) 14.85-15.17$ \\
\hline
\end{tabular}

PHQ-9 Patient Health Questionnaire-9, GAD-7 General Anxiety Disorder-7, LOT-R Revised Life Orientation Test, WHOQOL World health Organization Quality of Life, $Q 01$ How would you rate your quality of life?, Q02 How satisfied are you with your health? CI confidence Interval. SE Standard error, ${ }^{\text {a Scores }}$ adjusted for age, sex, duration of quarantine (in days) and Friend or family member with COVID-19. Effect size based on Cohen's $d$ concerning these outcomes between countries. In the Brazilian sample, the following significant results were found: (a) depressive symptoms were associated with lower age, not being a healthcare professional, and few days in social distancing; (b) Anxiety was associated with not being a healthcare professional and few days in social distancing; (c) Optimism was associated with higher age, lower alcohol use and not using daily medication and (d) Pessimism was associated with higher age, having family members/friends with COVID-19, not using a daily medication, not attending a primary health care unit, being a healthcare professional and few days in social distancing. In the Portuguese sample, the following significant results were found: (a) depressive symptoms were associated with female sex, lower age, not being a healthcare professional, and few days in social distancing; (b) Anxiety was associated with lower age, female sex, greater use of alcohol, not practicing physical activity and not being a healthcare professional; (c) Pessimism was associated with higher age.

Concerning the quality of life (Table 4), the multivariate GLM regression model revealed a significant main effect for age (Wilks's Lambda $=0.974, \mathrm{~F}=6.900, p<0.001$ ), sex (Wilks's Lambda $=0.992, \mathrm{~F}=2.063, p=0.036$ ), family members/friends with COVID-19 (Wilks's Lambda $=0.991$, $\mathrm{F}=2.376, p=0.015$ ), healthcare professionals (Wilks's Lambda $=0.985, \mathrm{~F}=3.946, p<0.001)$, and alcohol consumption (Wilks's Lambda $=0.991, \mathrm{~F}=2.252, p=0.021$ ), showing that there are differences between countries in relation to these variables. In the Brazilian sample, the following significant results were found: (a) Physical QOL was associated with male sex, not using daily medications and being a health professional; (b) Psychological QOL was associated with male sex, not using a daily medication, consulting a doctor/psychologist, being a healthcare professional and more days in social distancing; (c) Social Relationship QOL was associated with not visiting a primary health care unit; (d) Environmental QOL was associated with male sex, being a healthcare professional and not having family members/ friends with COVID-19. In the Portuguese sample, the following significant results were found: (a) Physical QOL was associated with practicing physical activity and more days in social distancing; (b) Psychological QOL: was associated with male sex, greater age, practicing physical activity and being a healthcare professional; (c) Social Relationship QOL was associated with more days in social distancing.

\section{Discussion}

Our results showed that there were remarkable differences between Brazil and Portugal concerning mental health and quality of life during the COVID-19 pandemic. If on the one hand, Brazilian individuals experienced more depressive and anxiety symptoms and lower levels of quality of life; on the other hand, they have higher levels of optimism as compared to Portuguese individuals. Several factors were associated with the mental health and quality of life for both samples, such as gender, age, being a healthcare professional, and days in social distancing. Other factors were relevant in specific contexts such as medication use, attending primary health care units, consulting doctors, use of alcohol, having a family with COVID-19, practicing physical activity, and having chronic diseases. These results could help health managers and healthcare professionals to develop preventive 
Table 3 Mental health univariate GLM regression analysis between Brazilian $(n=1156)$ and Portuguese $(n=913)$ during COVID-19 pandemic

\begin{tabular}{llll}
$\begin{array}{l}\text { Depressive symptoms } \\
\text { PHQ-9 }\end{array}$ & Anxiety & Optimism & Pessimism \\
$\beta(\mathrm{SE}), p$-value & GAD-7 & LOT-R Optimism & LOT-R Pessimism \\
\hline
\end{tabular}

\begin{tabular}{|c|c|c|c|c|}
\hline \multicolumn{5}{|l|}{ Age } \\
\hline Brazil & $-0.034(0.015), 0.020$ & $-0.022(0.013), 0.092$ & $0.040(0.007), .<0.001$ & $0.021(0.006), 0.001$ \\
\hline Portugal & $-0.066(0.015),<0.001$ & $-0.073(0.014),<0.001$ & 0.001 (0.007), 0.867 & 0.023 (0.007), 0.001 \\
\hline \multicolumn{5}{|l|}{ Sex } \\
\hline Brazil & $0.102(0.371), 0.783$ & $-0.503(0.338), 0.137$ & $-0.224(0.169), 0.185$ & 0.095 (0.163), 0.560 \\
\hline Portugal & 1.23 (0.415), 0.003 & $0.935(0.380), 0.014$ & -0.407 (0.190), 0.032 & $-0.113(0.183), 0.537$ \\
\hline \multicolumn{5}{|c|}{ Marital status } \\
\hline Brazil & 0.042 (389), 0.914 & 0.157 (0.352), 0.656 & $0.050(0.176), 0.775$ & $-0.103(0.170), 0.543$ \\
\hline Portugal & -0.242 (0.399), 0.544 & $-0.307(0.368), 0.404$ & $0.143(0.183), 0.437$ & 0.014 (0.177), 0.938 \\
\hline \multicolumn{5}{|c|}{ Physical activity ${ }^{\mathrm{a}}$} \\
\hline Brazil & 0.108 (0.878), 0.902 & $-0.381(0.348), 0.275$ & 0.236 (0.174), 0.175 & $-0.173(0.168), 0.303$ \\
\hline Portugal & $-0.602(0.794), 449$ & -0.912 (0.372), 0.014 & 0.163 (0.186), 0.381 & 0.324 (0.179), 0.070 \\
\hline \multicolumn{5}{|c|}{ Alcohol use } \\
\hline Brazil & $-0.214(0.360),-0.595$ & -0.249 (323), 0.441 & $0.318(0.161), 0.048$ & $-0.054(0.156), 0.731$ \\
\hline Portugal & -0.433 (0.392), 0.269 & $-0.699(0.352), 0.047$ & $0.137(176), 0.434$ & $0.289(0.170), 0.089$ \\
\hline \multicolumn{5}{|c|}{ Chronic Illness } \\
\hline Brazil & 0.848 (0.492), 0.085 & 0.409 (0.442), 0.355 & $0.168(0.220), 0.446$ & $-0.211(0.213), 0.322$ \\
\hline Portugal & $-0.247(0.555), 0.656$ & $-0.158(0.500), 0.752$ & $0.634(0.250), 0.011$ & $-0.018(0.241), 0.941$ \\
\hline \multicolumn{5}{|c|}{ Daily medication } \\
\hline Brazil & $0.822(0.420), 0.051$ & 0.697 (0.379), 0.066 & $-0.7490 .189),<0.001$ & $-0.571(0.183), 0.002$ \\
\hline Portugal & 0.569 (0.502), 0.258 & 0.460 (0.451), 0.308 & $-0.310(0.225), 0.168$ & -0.103 (0.217), 0.635 \\
\hline \multicolumn{5}{|c|}{ Doctor/psychologist consultation } \\
\hline Brazil & $0.468(0.442), 0.290$ & 0.773 (397), 0.051 & $-0.283(0.198), 0.152$ & $-0.248(0.191), 0.195$ \\
\hline Portugal & $0.420(771), 0.586$ & 0.402 (0.693), 0.561 & $-0.718(0.345), 0.038$ & 0.120 (334), 0.360 \\
\hline \multicolumn{5}{|c|}{ Primary health care unit } \\
\hline Brazil & $0.926(0.583), 112$ & $0.546(0.523), 0.297$ & $-0.422(0.261), 0.106$ & $-0.639(0.252), 0.011$ \\
\hline Portugal & -0.695 (0.695), 0.317 & $-0.528(624), 0.397$ & $0.581(0.311), 0.062$ & $0.044(0.300), 0.885$ \\
\hline \multicolumn{5}{|c|}{ Healthcare professional } \\
\hline Brazil & $-0.1 .486(0.407),<0.001$ & $-0.909(0.365), 0.013$ & 0.277 (0.182), 0.129 & $0.437(0.176), 0.013$ \\
\hline Portugal & $-1.392(0.463), 0.003$ & $-1.012(0.415), 0.015$ & 0.050 (0.207), 0.809 & $0.388(0.200), 0.052$ \\
\hline \multicolumn{5}{|c|}{ Friend/Family with COVID-19 } \\
\hline Brazil & 0.103 (0.409), 0.801 & $-0.256(0.367), 0.486$ & -0.203 (0.183), 0.267 & 0.389 (0.177), 0.028 \\
\hline Portugal & -0.760 (0.595), 0.202 & $-0.589(0.535), 0.271$ & 0.424 (0.267), 0.112 & $0.412(0.258), 0.110$ \\
\hline \multicolumn{5}{|c|}{ Social distancing duration (days) } \\
\hline Brazil & -0.023 (0.009), 0.010 & $-0.035(0.008),<0.001$ & $-0.001(0.004), 0.753$ & -0.369 (0.252), 0.011 \\
\hline Portugal & $-0.021(0.009), 0.026$ & $-0.006(0.008), 0.451$ & 0.005 (0.004), 0.209 & $0.004(0.004), 0.293$ \\
\hline
\end{tabular}

${ }^{a}$ Regular (at least 3 times a week). PHQ-9 Patient Health Questionnaire-9, GAD-7 General Anxiety Disorder-7, LOT-R Revised Life Orientation Test, SE Standard error, GLM General linear model. *Country: interaction

and therapeutic strategies in order to overcome the consequences of the social distancing and the pandemic.

The differences between countries reveal that cultural and social backgrounds may influence the impact of the COVID-19 on the mental health of individuals, and several hypotheses could help explaining these findings. First, although both countries have a similar language and Brazil has its roots on the Portuguese culture, it is important to note that Brazil is a low to middle-income and low educated country. In such countries, health literacy is a crucial factor for preventing, understanding, and managing infectious diseases such as COVID-19 [33]. When compared to Portugal, Brazil has a population with low health literacy. This can have an important influence on the interpretation and decision-making of the population that, in other words, may impact health, mental health, and QoL outcomes during the 
Table 4 Quality of life multivariate GLM regression analysis between Brazilian $(n=1156)$ and Portuguese $(n=913)$ during COVID-19 pandemic

\begin{tabular}{|c|c|c|c|c|}
\hline Variables & $\begin{array}{l}\text { Physical health } \\
\beta \text { (SE), } p \text {-value }\end{array}$ & $\begin{array}{l}\text { Psychological } \\
\beta \text { (SE), } p \text {-value }\end{array}$ & $\begin{array}{l}\text { Social relationships } \\
\beta \text { (SE), } p \text {-value }\end{array}$ & $\begin{array}{l}\text { Environment } \\
\beta \text { (SE), } p \text {-value }\end{array}$ \\
\hline \multicolumn{5}{|l|}{ Age } \\
\hline Brazil & $0.001(0.006), 0.895$ & 0.012 (0.006), 0.054 & 0.010 (0.008), 0.221 & 0.006 (0.006), 0.324 \\
\hline Portugal & $-0.002(0.006), 0.737$ & $0.031(0.007),<0.001$ & $0.008(0.008), 0.339$ & $0.001(0.006), 0.874$ \\
\hline \multicolumn{5}{|l|}{ Sex } \\
\hline Brazil & $-0.297(0.150), 0.049$ & $-0.432(0.165), 0.009$ & -0.359 (0.207), 0.083 & $-0.381(0.147), 0.009$ \\
\hline Portugal & $-0.253(, 169), 0.135$ & $-0.567(0.185), 0.002$ & $-0.338(0.232), 0.146$ & $-0.250(0.165), 0.130$ \\
\hline \multicolumn{5}{|c|}{ Marital status } \\
\hline Brazil & 0.065 (0.157), 0.680 & $-0.042(0.171), 0.804$ & $0.027(0.215), 0.899$ & $-0.070(0.153), 0.645$ \\
\hline Portugal & 0.242 (0.164), 0.138 & 0.129 (0.179), 0.470 & $-0.030(0.225), 0.893$ & 0.044 (0.159), 0.784 \\
\hline \multicolumn{5}{|c|}{ Physical activity ${ }^{\mathrm{a}}$} \\
\hline Brazil & 0.177 (0.155), 0.253 & 0.165 (0.170), 0.332 & $0.039(0.231), 0.856$ & $0.135(0.151), 0.372$ \\
\hline Portugal & 0.463 (0.166), 0.005 & $0.498(0.181), 0.006$ & 0.398 (0.228), 0.080 & $0.270(0.161), 0.095$ \\
\hline \multicolumn{5}{|c|}{ Chronic disease } \\
\hline Brazil & 0.074 (0.197), 0.707 & $-0.123(0.215), 0.568$ & $-0.282(0.270), 0.297$ & -0.117 (0.192). 0.542 \\
\hline Portugal & $0.100(0.223), 0.652$ & $0.182(0.244), 0.455$ & -0.339 (0.306), 0.268 & -0.063 (0.217), 0.770 \\
\hline \multicolumn{5}{|c|}{ Daily medication } \\
\hline Brazil & -0.393 (0.169), 0.020 & $-0.451(0.184), 0.015$ & $-0.345(0.232), 0.136$ & $-0.144(0.164), 0.380$ \\
\hline Portugal & $-0.187(0.201), 0.352$ & $-0.140(0.220), 0.525$ & $-0.109(0.276), 0.692$ & $-0.168(0.196), 0.392$ \\
\hline \multicolumn{5}{|c|}{ Alcohol use } \\
\hline Brazil & $-0.184(0.144), 0.201$ & 0.269 (0.157), 0.087 & $0.218(0.197), 0.270$ & $-0.096(0.140), 0.495$ \\
\hline Portugal & 0.054 (0.157), 0.732 & $0.117(0.171), 0.494$ & $-0.003(0.215), 0.989$ & -0.050 (0.153), 0.744 \\
\hline \multicolumn{5}{|c|}{ Doctor/psychologist consultation } \\
\hline Brazil & $0.194(0.177), 0.273$ & $0.382(0.193), 0.048$ & 0.337 (0.243), 0.165 & 0.249 (0.172), 0.148 \\
\hline Portugal & $-0.417(0.308), 0.176$ & $-0.451(0.337), 0.181$ & $0.331(0.423), 0.435$ & $0.062(0.300), 0.835$ \\
\hline \multicolumn{5}{|c|}{ Primary health care unit } \\
\hline Brazil & $-0.203(0.233), 0.382$ & $-0.310(0.255), 0.223$ & $-0.633(0.320), 0.048$ & $-0.334(0.227), 0.141$ \\
\hline Portugal & $0.016(0.277), 0.954$ & $0.438(0.304), 0.149$ & $0.054(0.381), 0.886$ & $0.001(0.270), 0.998$ \\
\hline \multicolumn{5}{|c|}{ Healthcare professional } \\
\hline Brazil & $0.558(0.162), 0.001$ & $0.805(0.178),<0.001$ & $0.341(0.223), 0.126$ & $0.586(0.158),<0.001$ \\
\hline Portugal & $0.347(0.185), 0.061$ & 0.490 (0.202), 0.015 & $0.488(0.254), 0.055$ & $0.205(0.180), 0.256$ \\
\hline \multicolumn{5}{|c|}{ Friend/Family with COVID-19 } \\
\hline Brazil & $-0.168(0.163), 0.305$ & -0.028 (0.179), 0.877 & $-0.433(0.224), 0.054$ & $-0.463(0.159), 0.004$ \\
\hline Portugal & $0.395(0.238), 0.097$ & $0.501(0.260), 0.055$ & $0.490(0.327), 0.134$ & $0.126(0.232), 0.587$ \\
\hline \multicolumn{5}{|c|}{ Social distancing duration (days) } \\
\hline Brazil & 0.005 (0.004), 0.185 & $0.008(0.004), 0.046$ & $0.001(0.005), 0.790$ & 0.005 (0.004), 0.135 \\
\hline Portugal & 0.008 (0.004), 0.035 & 0.007 (0.004), 0.095 & 0.010 (0.005), 0.042 & 0.004 (0.004), 0.229 \\
\hline
\end{tabular}

${ }^{a}$ Regular (at least 3 times a week). *Country: interaction. GLM General linear model

pandemic [33]. This Brazilian characteristic may be one of the responsible for the higher prevalence of mental health problems in Brazil as compared to Portugal.

Second, another possible explanation is the important inequalities faced in Brazil [34], which may be responsible for: (a) worse living conditions (i.e., small households, shared rooms, poor sanitation), leading to a greater dissemination of the virus and a more vulnerability to infection; (b) important economic difficulties (e.g., high unemployment rates), making individuals search for jobs and not respecting the social distancing; (c) limited access to healthcare, which increases the high rates of mortality and distress among the population; (d) poor access to high-speed internet, limiting real-time information; and (e) low education levels, which may be associated with taboos and misconceptions [35, 36]. This explanation has been already noted by previous studies, which showed that 
low socioeconomic status is related to greater barriers to physical distancing [37] and higher death rates [38].

Third, the political scenario in both countries may have resulted in different approaches towards fighting the pandemic [39]. In Brazil, the crisis triggered by the COVID-19 pandemic was not considered a public health problem, but rather a threat to the economy [7]. In this context, although Brazil instituted the quarantine before Portugal, Portugal has tested a greater number of individuals as compared to Brazil, and the Portuguese quarantine was much more effective [40]. These findings may support the fact that countries with different characteristics may suffer differently from the COVID-19 pandemic.

It is interesting to note that, despite the fact that the mental health of Brazilians was worse than in the Portuguese individuals, the optimism was higher and the pessimism was lower. A previous study [41] has confirmed these findings showing that Brazilians tend to have a greater optimism as compared to Portugeses. Another hypothesis is that those individuals with greater pessimism are probably more prone to have fear, and this fear may make them search more for available information concerning the virus [42]. Speculating, we argue that in the COVID-19 outbreak, related fear can boost the risk of pessimist feelings, particularly in those who have more information and have closer contact with the disease.

Concerning the associated factors, our study was able to identify common patterns between countries. Although previous studies have reported a lower prevalence of depression and anxiety in the general population as compared to healthcare professionals [43], in our study, contrary to our expectations, healthcare professionals had better mental health and well-being. A recent systematic review [44] found that healthcare professionals during COVID-19 had lower levels of fear and post-traumatic stress disorder, similar levels of psychological distress and higher levels of anxiety and depression as compared to the general population. Nevertheless, other systematic reviews $[14,45]$ have found similar rates of depression and anxiety for both groups. Although there is no clear explanation to our findings, healthcare professionals may have a high resilience [46], a high educational level and, better training and knowledge of the disease [47], which may help mitigating their suffering. However, it is important to underscore that the present study does not have information on whether those included professionals were on the front lines or not.

The days in social distancing were associated with lower levels of mental health problems in our study. This is somewhat different from previous findings, which showed that social distancing was related to depressive and anxiety symptoms [48]. In the case of Brazil, some hypotheses may justify this result, such as the fact that not respecting the social distancing could be a matter of economic necessity since the rates of unemployment were high during the pandemic [49] and the limited access to healthcare. However, the high rates of domestic violence identified during the pandemic in Brazil $[50,51]$ could also be associated with greater distress in those staying at home. In contrast to the Brazilian scenario, domestic violence in Portugal seems to have dropped during the COVID-19 pandemic. The Portuguese government carried out specific actions to fight and raise awareness, which may have positively impacted the reduction of domestic violence during the COVID-19 pandemic [52].

Corroborated by several studies, we also found that females were more prone to present mental health problems and had lower levels of optimism than males. These results are fully supported by previous evidence [45, 53, 54] and denote a high vulnerability of women during the pandemic [55]. Previous studies have shown that the pandemic has increased the challenges, the responsibility, the inequality, and lower women's income $[55,56]$. Health managers should be aware of this vulnerability and propose interventions focusing on the well-being of women during times of crisis.

Age was another important factor related to mental health in our sample. Older participants had lower levels of depression and anxiety but were also more pessimism than younger participants. A recent study in China [57] during the COVID-19 pandemic found that younger individuals (less than 35 years old) had higher depressive and anxiety symptoms as compared to those with more than 35 years old. The same results were found in Spain [58], where older adults ( 65 years old or more) had lower levels of mental health problems as compared to other groups. Some authors argue that the explanation for such findings could be related to the stress faced by students and young adults in order to adapt to the new reality of online education and home office [58].

Physical activity was another important factor strongly related to a better mental health status but limited to the Portuguese sample. Despite the restrictions imposed by social distancing, several studies have shown the benefits of exercise to mental health $[59,60]$. This was also noted in the context of the COVID-19 pandemic as well [61]. The mechanisms for these benefits include an increase in neurogenesis, the reduction of inflammatory and oxidant markers and improvements in self-esteem [61].

Finally, chronic diseases, use of daily medications and attending medical consultations were associated with worse mental health among Brazilian participants. This is expected since those with high comorbidity usually have a higher prevalence of mental disorders, as supported by a previous study [62]. Likewise, due to the cross-sectional nature of our study, those with psychological distress tend to search for a doctor and be prescribed medications. 


\section{Clinical implication}

Our findings have clinical implications that should be highlighted. First, the peculiarities of each country in this study deserve further attention. Politicians and Health managers should be aware that there are remarkable differences concerning social and economic backgrounds that should be taken into consideration by health systems and organizations. Thus, some measures that could be very effective in one context could fail to achieve success in other contexts. Second, in spite of these differences, some factors seem to be associated with mental health for both countries. Female individuals, for instance, seem to be more vulnerable to suffering during the pandemic and this specific groups should be considered for future preventive interventions. Physical activity was associated with better outcomes in Portugal and should be encouraged by governments even in the scenario of social distancing. Although in our study, health professionals had lower rates of mental health problems, they are in a vulnerable condition and should be supported by managers, providing appropriate protective equipment, psychological support, and minimizing workloads [6]. Finally, those not respecting social distancing should be followed in order to understand why they are away from their homes. Social interventions could be important strategies to minimize economic problems that may result in not respecting government laws.

\section{Limitation}

The present study has several limitations that should be considered while interpreting its results. This is a cross-sectional study, not allowing the differentiation of what is cause and what is the effect. Future longitudinal studies are needed. Although our sample can be considered large and most territories were represented, it was not a representative survey of both countries, i. e., $83 \%$ of the Brazilian participants were from the Southeast region and $78.4 \%$ were from the Southern region of Portugal. Therefore, generalizability should be made with caution. Another concern is the selection bias related to the Internet access since our survey was online. Although Portugal is a smaller and richer country and, for this reason, Internet access seems to be higher; previous research carried out in 2019 found that the coverage of Internet is quite similar between countries (i.e., $82.7 \%$ in Brazil's and $80.9 \%$ in Portugal). However, it is important to note that some places in both countries have limited access and, particularly for older persons. The questionnaires used in this study were validated and worldwide used to assess mental health and QoL. However, it is important to note that they were based on self-reported measures and assessed only symptoms, not implying diagnosis. The samples have misbalances concerning age, sex, marital status, use of medications, and use of alcohol. Despite the fact that we have adjusted for these confounding variables in the statistical models, this may have also influenced our findings. Likewise, the present study has not assessed measurement invariance across the two countries, and this could be considered a limitation of the present study. Another limitation of the study is the lack of data on people who did not respect social distancing. Future research comparing the outcomes addressed between social distancing followers and non-followers is important. Finally, the socio-cultural level of the participants has not been assessed. It is well-known that culture has an important role on a person's beliefs, norms, and values. This may have an influence on the way people seek health behaviors, such as attending mental health consultations and adhering to preventive lifestyles or treatments [63].

\section{Conclusion}

In conclusion, despite the fact that Brazilians were more optimistic during the COVID-19 pandemic, they had lower levels of mental health and QoL as compared to the Portuguese individuals. Factors such as age, sex, days in social distancing, and being a healthcare professional were associated with mental health outcomes in both samples. Health managers and government should be aware of the cultural, political, and economic differences in order to provide individualized care during COVID-19 pandemic.

Supplementary Information The online version contains supplementary material available at https://doi.org/10.1007/s11136-021-03031-9.

Acknowledgements We thank all participants of this study.

Author contributions This article is the work of the authors. LMV, GHYJ, and CT conceived, designed the study, and managed online data collection. LMV analyzed the data. LMV, LS; GL, OMSV, and HJ made the discussion and the conclusions. All the authors interpreted the data, drafted the manuscript, and criticized it for relevant intellectual content. All authors have approved the final version of the manuscript.

Funding Not applied.

Data availability Additional detailed data for this study is available upon reasonable written request to the corresponding author.

\section{Declarations}

Conflict of interest The Author(s) declare(s) that there is no conflict of interest.

\section{References}

1. Del Rio, C., \& Malani, P. N. (2020). COVID-19-new insights on a rapidly changing epidemic. JAMA, 323(14), 1339-1340. https:// doi.org/10.1001/jama.2020.3072 
2. Yuan, J., Li, M., Lv, G., \& Lu, Z. K. (2020). Monitoring transmissibility and mortality of COVID-19 in Europe. International Journal of Infectious Diseases, 95, 311-315. https://doi.org/10. 1016/j.ijid.2020.03.050

3. Tang, Y., Serdan, T. D. A., Masi, L. N., Tang, S., Gorjao, R., \& Hirabara, S. M. (2020). Epidemiology of COVID-19 in Brazil: Using a mathematical model to estimate the outbreak peak and temporal evolution. Emerging Microbes \& Infections, 9(1), 1453-1456.

4. Moghadas, S. M., Shoukat, A., Fitzpatrick, M. C., Wells, C. R., Sah, P., Pandey, A., Sachs, J. D., Wang, Z., Meyers, L. A., Singer, B. H., \& Galvani, A. P. (2020). Projecting hospital utilization during the COVID-19 outbreaks in the United States. Proceedings of the National Academy of Sciences, 117(16), 9122-9126. https:// doi.org/10.1073/pnas.2004064117

5. Coimbra, M., Paixão, C., \& Ferreira, C. (2021). Exploring eating and exercise-related indicators during COVID-19 quarantine in Portugal: Concerns and routine changes in women with different BMI. Eating and Weight Disorders. https://doi.org/10.1007/ s40519-021-01163-y

6. França, A. B., Trzesniak, C., Schelini, P. W., Junior, G. H. Y., \& Vitorino, L. M. (2021). Exploring depressive symptoms among healthcare professionals and the general population during the COVID-19 pandemic in Brazil. Psychological Reports. https:// doi.org/10.1177/00332941211025264

7. The, L. (2020). COVID-19 in Brazil: "So what?" Lancet (London, England), 395(10235), 1461-1461. https://doi.org/10.1016/ S0140-6736(20)31095-3

8. Lewnard, J. A., \& Lo, N. C. (2020). Scientific and ethical basis for social-distancing interventions against COVID-19. The Lancet Infectious Diseases, 20(6), 631-633. https://doi.org/10.1016/ s1473-3099(20)30190-0

9. Venkatesh, A., \& Edirappuli, S. (2020). Social distancing in covid-19: What are the mental health implications? BMJ, 369, m1379. https://doi.org/10.1136/bmj.m1379

10. Galea, S., Merchant, R. M., \& Lurie, N. (2020). The mental health consequences of COVID-19 and physical distancing: the need for prevention and early intervention. JAMA Internal Medicine, 180(6), 817-818. https://doi.org/10.1001/jamainternmed.2020. 1562

11. Estela, M. L., Aquino, I. H., Silveira, J. M., Pescarini, R., de Aquino, J. A., dos Souza-Filho, A., Santosocha, A., Ferreira, A., Victor, C., Teixeira, D. B., Machado, E., Paixão, F. J. O., Alves, F., Pilecco, G., Menezes, L., Gabrielli, L., de Leite, M. C. C., Almeida, N., Ortelan, Q. H. R., ... Lima, Reis Silva. (2020). Social distancing measures to control the COVID-19 pandemic: potential impacts and challenges in Brazil. Ciência \& Saúde Coletiva, 25(suppl 1), 2423-2446. https://doi.org/10.1590/1413-81232 020256.1.10502020(Medidasdedistanciamentosocialnocontroled apandemiadeCOVID-19:potenciaisimpactosedesafiosnoBrasil.)

12. Vitorino, L. M., Yoshinari Júnior, G. H., Gonzaga, G., Dias, I. F., Pereira, J. P. L., Ribeiro, I. M. G., França, A. B., Al-Zaben, F., Koenig, H. G., \& Trzesniak, C. (2021). Factors associated with mental health and quality of life during the COVID-19 pandemic in Brazil. BJPsych Open, 7(3), e103. https://doi.org/10.1192/bjo. 2021.62

13. Vieira, D. A., \& Meirinhos, V. (2021). COVID-19 lockdown in portugal: Challenges, strategies and effects on mental health. Trends in Psychology, 29(2), 354-374. https://doi.org/10.1007/ s43076-021-00066-2

14. Pappa, S., Ntella, V., Giannakas, T., Giannakoulis, V. G., Papoutsi, E., \& Katsaounou, P. (2020). Prevalence of depression, anxiety, and insomnia among healthcare workers during the COVID-19 pandemic: A systematic review and meta-analysis. Brain, behavior, and immunity, 88, 901-907. https://doi.org/10.1016/j.bbi. 2020.05.026
15. Xiong, Jiaqi, Lipsitz, Orly, Nasri, Flora, Lui, Leanna M.W.., Gill, Hartej, Phan, Lee, Chen-Li, David, Iacobucci, Michelle, Ho, Roger, Majeed, Amna, \& McIntyre, Roger S. (2020). Impact of COVID-19 pandemic on mental health in the general population: A systematic review. Journal of Affective Disorders, 277, 55-64. https://doi.org/10.1016/j.jad.2020.08.001

16. Depression, W. J. G. W. H. O. (2017). Other common mental disorders: Global health estimates. 1-24.

17. Nochaiwong, S., Ruengorn, C., Thavorn, K., Hutton, B., Awiphan, R., Phosuya, C., Ruanta, Y., \& Wongpakaran, T. (2021). Global prevalence of mental health issues among the general population during the coronavirus disease-2019 pandemic: A systematic review and meta-analysis. Science and Reports, 11(1), 10173. https://doi.org/10.1038/s41598-021-89700-8

18. Baiyewu, O., Elugbadebo, O., \& Oshodi, Y. (2020). Burden of COVID-19 on mental health of older adults in a fragile healthcare system: The case of Nigeria: Dealing with inequalities and inadequacies. International psychogeriatrics, 32(10), 1181-1185. https://doi.org/10.1017/S1041610220001726

19. Vahedian-Azimi, A., Moayed, M. S., Rahimibashar, F., Shojaei, S., Ashtari, S., \& Pourhoseingholi, M. A. (2020). Comparison of the severity of psychological distress among four groups of an Iranian population regarding COVID-19 pandemic. BMC Psychiatry, 20(1), 402. https://doi.org/10.1186/s12888-020-02804-9

20. Passos, L., Prazeres, F., Teixeira, A., \& Martins, C. (2020). Impact on mental health due to COVID-19 pandemic: Cross-sectional study in Portugal and Brazil. 17(18), 6794. https://www.mdpi. com/1660-4601/17/18/6794

21. Suppawittaya, P., Yiemphat, P., Yasri, P. J. I. J. o. s., \& research, h. (2020). Effects of social distancing, self-quarantine and selfisolation during the COVID-19 pandemic on people's well-being, and how to cope with it. 5(2), 12-20. http://www.inrein.com/ijshr/ IJSHR_Vol.5_Issue.2_April2020/IJSHR003.pdf

22. Granello, D. H., \& Wheaton, J. E. (2004). Online data collection: strategies for research. Journal of Counseling \& Development, 82(4), 387-393. https://doi.org/10.1002/j.1556-6678.2004.tb003 25.x

23. Zimmerman, M. (2019). Using the 9-item patient health questionnaire to screen for and monitor depression. JAMA, 322(21), 2125-2126. https://doi.org/10.1001/jama.2019.15883

24. Santos, I. S., Tavares, B. F., Munhoz, T. N., Almeida, L. S., Silva, N. T., Tams, B. D., Patella, A. M., \& Matijasevich, A. (2013). Sensitivity and specificity of the Patient Health Questionnaire-9 (PHQ-9) among adults from the general population. Cadernos de Saúde Pública, 29(8), 1533-1543. https://doi.org/10.1590/0102311x00144612(SensibilidadeeespecificidadedoPatientHealthQu estionnaire-9(PHQ-9)entreadultosdapopulaçãogeral.)

25. Spitzer, R. L., Kroenke, K., Williams, J. B., \& Löwe, B. (2006). A brief measure for assessing generalized anxiety disorder: The GAD-7. Archives of Internal Medicine, 166(10), 1092-1097. https://doi.org/10.1001/archinte.166.10.1092

26. Sousa, T. V., Viveiros, V., Chai, M. V., Vicente, F. L., Jesus, G., Carnot, M. J., Gordo, A. N. C., \& Ferreira, P. L. (2015). Reliability and validity of the Portuguese version of the Generalized Anxiety Disorder (GAD-7) scale. Health and Quality of Life Outcomes, 13, 50. https://doi.org/10.1186/s12955-015-0244-2

27. Bandeira, M., Bekou, V., Lott, K. S., Teixeira, M. A., \& Rocha, S. S. J. E. (2002). Validação transcultural do Teste de Orientação da Vida (TOV-R). Estudos de Psicologia (Natal), 7, 251-258.

28. Fleck, M., Louzada, S., Xavier, M., Chachamovich, E., Vieira, G., Santos, L., \& Pinzon, V. (2000). Aplicação da versão em português do instrumento abreviado de avaliação da qualidade de vida" WHOQOL-bref". Revista de Saúde Pública, 34, 178-183.

29. Medicine, W. G. J. P. (1998). Development of the World Health Organization WHOQOL-BREF quality of life assessment. 28(3), $551-558$. 
30. Cuijpers, P., Turner, E. H., Koole, S. L., van Dijke, A., \& Smit, F. (2014). What is the threshold for a clinically relevant effect? The case of major depressive disorders. Depression and Anxiety, 31(5), 374-378. https://doi.org/10.1002/da.22249

31. Toussaint, A., Hüsing, P., Gumz, A., Wingenfeld, K., Härter, M., Schramm, E., \& Löwe, B. (2020). Sensitivity to change and minimal clinically important difference of the 7-item Generalized Anxiety Disorder Questionnaire (GAD-7). Journal of Affective Disorders, 265, 395-401. https://doi.org/10.1016/j.jad. 2020.01 .032

32. Hays, R. D., \& Woolley, J. M. (2000). The concept of clinically meaningful difference in health-related quality-of-life research. How meaningful is it? Pharmacoeconomics, 18(5), 419-423. https://doi.org/10.2165/00019053-200018050-00001

33. Paakkari, L., \& Okan, O. (2020). COVID-19: Health literacy is an underestimated problem. Lancet Public Health, 5(5), e249e250. https://doi.org/10.1016/s2468-2667(20)30086-4

34. Landmann-Szwarcwald, C., \& Macinko, J. J. I. (2016). A panorama of health inequalities in Brazil. International Journal for Equity in Health, 15(1), 1-3.

35. Ahmed, F., Ahmed, N., Pissarides, C., \& Stiglitz, J. (2020). Why inequality could spread COVID-19. Lancet Public Health, 5(5), e240. https://doi.org/10.1016/s2468-2667(20)30085-2

36. Blustein, D. L., \& Guarino, P. A. J. J. o. H. P. (2020). Work and unemployment in the time of COVID-19: The existential experience of loss and fear. 60(5), 702-709.

37. Jay, J., Bor, J., Nsoesie, E. O., Lipson, S. K., Jones, D. K., Galea, S., \& Raifman, J. (2020). Neighbourhood income and physical distancing during the COVID-19 pandemic in the United States. Nature Human Behaviour, 4(12), 1294-1302. https://doi.org/10.1038/s41562-020-00998-2

38. Finch, W. H., \& Hernández Finch, M. E. (2020). Poverty and Covid-19: Rates of Incidence and Deaths in the United States During the First 10 Weeks of the Pandemic [Original Research]. 5(47). https://doi.org/10.3389/fsoc.2020.00047

39. Cash, R., \& Patel, V. (2020). Has COVID-19 subverted global health? Lancet (London, England), 395(10238), 1687-1688. https://doi.org/10.1016/S0140-6736(20)31089-8

40. Triunfol, M. (2020). High COVID-19 testing rate in Portugal. The Lancet Infectious Diseases, 20(7), 783. https://doi.org/10. 1016/s1473-3099(20)30499-0

41. Baranski, E., Sweeny, K., Gardiner, G., \& Funder, D. C. (2021). International optimism: Correlates and consequences of dispositional optimism across 61 countries. J Pers, 89(2), 288-304. https://doi.org/10.1111/jopy. 12582

42. Jovančević, A., \& Milićević, N. (2020). Optimism-pessimism, conspiracy theories and general trust as factors contributing to COVID-19 related behavior - A cross-cultural study. Personality and individual differences, 167, 110216-110216. https://doi. org/10.1016/j.paid.2020.110216

43. Mata, D. A., Ramos, M. A., Bansal, N., Khan, R., Guille, C., Di Angelantonio, E., \& Sen, S. (2015). Prevalence of depression and depressive symptoms among resident physicians: a systematic review and meta-analysis. JAMA, 314(22), 2373-2383.

44. Salazar de Pablo, G., Vaquerizo-Serrano, J., Catalan, A., Arango, C., Moreno, C., Ferre, F., Shin, J. I., Sullivan, S., Brondino, N., Solmi, M., \& Fusar-Poli, P. (2020). Impact of coronavirus syndromes on physical and mental health of health care workers: Systematic review and meta-analysis. Journal of Affective Disorders, 275, 48-57. https://doi.org/10.1016/j.jad. 2020.06.022

45. Luo, M., Guo, L., Yu, M., Jiang, W., \& Wang, H. (2020). The psychological and mental impact of coronavirus disease 2019 (COVID-19) on medical staff and general public - A systematic review and meta-analysis. Psychiatry Research, 291, 113190. https://doi.org/10.1016/j.psychres.2020.113190
46. Robertson, H. D., Elliott, A. M., Burton, C., Iversen, L., Murchie, P., Porteous, T., \& Matheson, C. (2016). Resilience of primary healthcare professionals: A systematic review. British Journal of General Practice, 66(647), e423-433. https://doi.org/10.3399/ bjgp16X685261

47. Tripathi, R., Alqahtani, S. S., Albarraq, A. A., Meraya, A. M., Tripathi, P., Banji, D., Alshahrani, S., Ahsan, W., \& Alnakhli, F. M. (2020). Awareness and preparedness of COVID-19 outbreak among healthcare workers and other residents of SouthWest Saudi Arabia: A cross-sectional survey. Frontiers in Public Health, 8, 482-482. https://doi.org/10.3389/fpubh.2020.00482

48. Peng, M., Mo, B., Liu, Y., Xu, M., Song, X., Liu, L., Fang, L., Guo, T., Ye, J., Yu, Z., Deng, Q., \& Zhang, X. (2020). Prevalence, risk factors and clinical correlates of depression in quarantined population during the COVID-19 outbreak. Journal of Affective Disorders, 275, 119-124. https://doi.org/10.1016/j.jad.2020.06. 035

49. Barberia, L. G., \& Gómez, E. J. (2020). Political and institutional perils of Brazil's COVID-19 crisis. Lancet (London, England), 396(10248), 367-368. https://doi.org/10.1016/S0140-6736(20) 31681-0

50. Marques, E. S., Moraes, C. L., Hasselmann, M. H., Deslandes, S. F., \& Reichenheim, M. E. (2020). Violence against women, children, and adolescents during the COVID-19 pandemic: Overview, contributing factors, and mitigating measures. Cadernos de Saúde Pública, 36(4), e00074420. https://doi.org/10.1590/0102-311x0 0074420

51. Valença, A. M., Telles, L. E., da Silva, A. G., \& Barros, A. J. (2021). The increasing risk of domestic violence, including parricide, during the COVID-19 pandemic: Reflections and recommendations. Braz J Psychiatry. https://doi.org/10.1590/ 1516-4446-2021-1896

52. Brink, J., Cullen, P., Beek, K., \& Peters, S. A. E. (2021). Intimate Partner Violence during the Covid-19 pandemic in Western and Southern European countries. European Journal of Public Health. ckab093. Advance online publication https://doi.org/10.1093/eurpub/ckab093

53. González-Sanguino, C., Ausín, B., Castellanos, M., Saiz, J., López-Gómez, A., Ugidos, C., \& Muñoz, M. (2020). Mental health consequences during the initial stage of the 2020 Coronavirus pandemic (COVID-19) in Spain. Brain, Behavior, and Immunity, 87, 172-176. https://doi.org/10.1016/j.bbi.2020.05.040

54. Liu, C., \& Wang, M. (2020). Prevalence and factors associated with depression in patients with COVID-19. Journal of Affective Disorders Reports, 2, 100042-100042. https://doi.org/10.1016/j. jadr.2020.100042

55. Power, K. (2020). The COVID-19 pandemic has increased the care burden of women and families. Sustainability Science, Practice and Policy, 16(1), 67-73. https://doi.org/10.1080/15487733.2020. 1776561

56. Carli, L. L. (2020). Women, Gender equality and COVID-19. Gender in Management: An International Journal.

57. Huang, Y., \& Zhao, N. (2020). Generalized anxiety disorder, depressive symptoms and sleep quality during COVID-19 outbreak in China: A web-based cross-sectional survey. Psychiatry Research, 288, 112954. https://doi.org/10.1016/j.psychres.2020. 112954

58. Ozamiz-Etxebarria, N., Dosil-Santamaria, M., Picaza-Gorrochategui, M., \& Idoiaga-Mondragon, N. (2020). Stress, anxiety, and depression levels in the initial stage of the COVID-19 outbreak in a population sample in the northern Spain. Cadernos de Saúde Pública, 36(4), e00054020. https://doi.org/10.1590/0102-311x0 0054020(Nivelesdeestrés, ansiedadydepresiónenlaprimerafasedelb rotedelCOVID-19enunamuestrarecogidaenelnortedeEspaña.)

59. McDowell, C. P., Dishman, R. K., Gordon, B. R., \& Herring, M. P. (2019). Physical activity and anxiety: A systematic review and 
meta-analysis of prospective cohort studies. American Journal of Preventive Medicine, 57(4), 545-556. https://doi.org/10.1016/j. amepre.2019.05.012

60. Schuch, Felipe B., Vancampfort, Davy, Firth, Joseph, Rosenbaum, Simon, Ward, Philip B., Silva, Edson S., Hallgren, Mats, Leon, Antonio Ponce De., Dunn, Andrea L., Deslandes, Andrea C., Fleck, Marcelo P., Carvalho, Andre F., \& Stubbs, B. (2018). Physical activity and incident depression: A meta-analysis of prospective cohort studies. American Journal of Psychiatry, 175(7), 631-648. https://doi.org/10.1176/appi.ajp.2018.17111194

61. Jacob, Louis, Tully, Mark A., Barnett, Yvonne, Lopez-Sanchez, Guillermo F., Butler, Laurie, Schuch, Felipe, López-Bueno, Rubén, McDermott, Daragh, Firth, Joseph, Grabovac, Igor, Yakkundi, Anita, Armstrong, Nicola, Young, Timothy, \& Smith, Lee. (2020). The relationship between physical activity and mental health in a sample of the UK public: A cross-sectional study during the implementation of COVID-19 social distancing measures. Mental Health and Physical Activity, 19, 100345-100345. https:// doi.org/10.1016/j.mhpa.2020.100345
62. Louvardi, M., Pelekasis, P., Chrousos, G. P., \& Darviri, C. (2020). Mental health in chronic disease patients during the COVID-19 quarantine in Greece. Palliative \& Supportive Care, 18(4), 394399. https://doi.org/10.1017/s1478951520000528

63. Lucchetti, G., Damiano, R. F., DiLalla, L. F., Lucchetti, A. L. G., Moutinho, I. L. D., da Silva Ezequiel, O., \& Kevin Dorsey, J. (2018). Cross-cultural differences in mental health, quality of life, empathy, and Burnout between US and Brazilian Medical Students. Academic Psychiatry, 42(1), 62-67. https://doi.org/10. 1007/s40596-017-0777-2

Publisher's Note Springer Nature remains neutral with regard to jurisdictional claims in published maps and institutional affiliations. 